\title{
Trends in residual stress for GaN/AIN/6H-SiC heterostructures
}

\author{
N. V. Edwards, ${ }^{\text {a) }}$ M. D. Bremser, ${ }^{\text {b) }}$ and R. F. Davis \\ Department of Materials Science and Engineering, North Carolina State University, Raleigh, \\ North Carolina 27695
}

A. D. Batchelor
Analytical Instrumentation Facility, North Carolina State University, Raleigh, North Carolina 27695

S. D. Yoo, C. F. Karan, and D. E. Aspnes

Department of Physics, North Carolina State University, Raleigh, North Carolina 27695

(Received 4 June 1998; accepted for publication 10 September 1998)

We discuss trends in residual stress as a function of film thickness, growth temperature, and substrate orientation for $\mathrm{GaN} / \mathrm{AlN} / 6 \mathrm{H}-\mathrm{SiC}$ heterostructures. Films are mostly compressive for samples less than about $0.7 \mu \mathrm{m}$ thick, are tensile up to about $2 \mu \mathrm{m}$, then abruptly become less tensile with stress values near 1 kbar thereafter. We interpret this as a successive relief of lattice mismatch and thermal stresses culminating in a catastrophic relief by unknown mechanisms at moderate thicknesses. These data indicate that relaxation processes in these heterostructures are not as well understood as previously supposed. (C) 1998 American Institute of Physics.

[S0003-6951(98)01845-2]

As evident from the wide range of published excitonic energy positions, ${ }^{1-5}$ residual stress in GaN clearly manifests itself in optical data. Samples grown under different conditions yield reflectance spectra with different line shapes and excitonic splittings due to different states of residual stress in the layers. However, this wide range typically results from the use of two very different substrate materials, $6 \mathrm{H}-\mathrm{SiC}$ and $\mathrm{Al}_{2} \mathrm{O}_{3}$, rather than from achieving a wide variety of stresses on a single type of substrate. ${ }^{6}$ Optical data in the literature give the impression that compressive stress is the inevitable result of growth on $\mathrm{Al}_{2} \mathrm{O}_{3}$ substrates, ${ }^{1,2,4}$ while the relative scarcity of data for $\mathrm{GaN}$ on $6 \mathrm{H}-\mathrm{SiC}$ has reinforced the impression that only tensile material can be grown on this substrate. ${ }^{3-5}$

Here, we show that such observations are simply a result of growth in the regime where $\mathrm{GaN}$ on $6 \mathrm{H}-\mathrm{SiC}$ is tensile. This is done in the context of reporting empirical trends in residual stress for selected growth parameters in simple $6 \mathrm{H}-$ $\mathrm{SiC}$ substrate/AlN buffer/GaN film heterostructures representing the widest range of stress reported thus far for this substrate material. ${ }^{5}$ We show that compressive GaN layers are indeed achievable on this substrate, further supporting our earlier hypothesis ${ }^{5}$ that there is no a priori correlation between substrate material and residual stress. But this relatively large collection of data clearly indicates that relaxation phenomena in these simple heterostructures are not well understood.

Optical data were obtained with a single-beam lowtemperature reflectometer consisting of a Xe arc lamp and a Cary 14 monochromator. Resolution was better than $1 \mathrm{meV}$ at $3.4 \mathrm{eV}$. Measurements were done on samples cooled to 10 $\mathrm{K}$ with an Air Products cryotip. We examined thirty GaN layers grown by metalorganic chemical vapor deposition

\footnotetext{
${ }^{a)}$ Present address: Linköpings Universitet, IFM/Materiefysik, S-58183 Linköping, Sweden. Electronic mail: ginger@ifm.liu.se

b) Present address: Aixtron Inc., 1569 Barclay Blvd. Buffalo Grover, IL 60089.
}

(MOCVD) on 6H-SiC substrates. All samples were undoped, were grown with the same $\mathrm{V}$-III flux ratio, have $1000 \AA$ thick AlN buffer layers grown at $1000^{\circ} \mathrm{C}$, and were subject to the same postgrowth rate of cooling. Details of crystal growth are given elsewhere. ${ }^{7}$ Reflectance line shapes were analyzed in reciprocal space to yield the energies $E_{A}$, $E_{B}$, and $E_{C}$ of the $A, B$, and $C$ excitons associated with the $\Gamma_{9}, \Gamma_{7}$, and $\Gamma_{7}$ valence bands, respectively, to within \pm 0.5 meV. ${ }^{5,8}$ Residual in-plane stresses $\sigma_{x x}=\sigma_{y y}=\sigma_{11}$ were estimated to within an additive constant $E_{A 0}$ from the measured critical point energy $E_{A}$ as described previously. ${ }^{5}$ Film thicknesses were measured in cross section to within 5\% using a JEOL 6400FE field emission scanning electron microscope (FE-SEM) and verified by the reflectance data below the band edge.

As stated previously, by conventional wisdom simple structures grown on $\mathrm{Al}_{2} \mathrm{O}_{3}$ are in compression ${ }^{9-12}$ while those grown on $6 \mathrm{H}-\mathrm{SiC}$ are in tension. ${ }^{3,9,13,14}$ It is usually assumed for growth on $6 \mathrm{H}-\mathrm{SiC}$ that compressive latticemismatch stresses ${ }^{11,12}$ are relieved after a few nanometers of growth $^{15}$ and tensile thermal mismatch stresses ${ }^{11,12}$ persist thereafter. To investigate these issues we plot $E_{A}$ and $\sigma_{x x}$ values for the samples versus film thickness in Fig. 1, versus growth temperature in Fig. 2, and compare on-axis and vicinal samples in Fig. 3. From Fig. 1 we find that we can classify these films as very thin $(\sim 0.7 \mu \mathrm{m})$, moderately thick $(\sim 0.7$ to $\sim 1.9 \mu \mathrm{m})$, or very thick $(>1.9 \mu \mathrm{m})$ according to their residual stress. Some global trends are evident in Fig. 1, independent of growth temperature or offcut angle. Contrary to conventional wisdom, very thin samples are generally in compression. ${ }^{16}$ Moderately thick samples are in tension with stress typically increasing with thickness up to a critical thickness somewhere near 2-3 $\mu \mathrm{m}$. Above this critical thickness, samples are in tension at a reduced stress of $\sim 1$ kbar. It appears that the relaxation process occurs more gradually - or that lattice and thermal mismatch stresses are more complex - than expected for these materials.

We interpret this behavior as a progressive relaxation of 


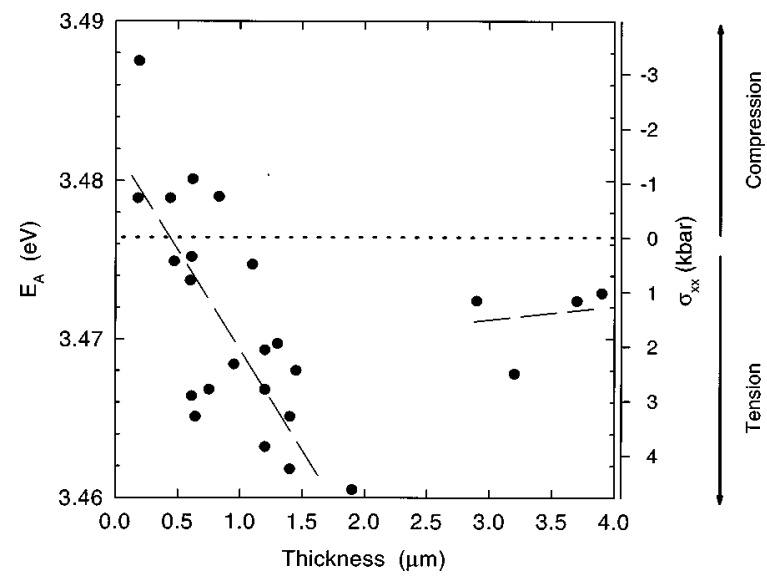

FIG. 1. $E_{A}$ and $\sigma_{x x}$ vs thickness $d$ for GaN films on $6 \mathrm{H}-\mathrm{SiC}$. Lines are shown to guide the eye.

compressive stresses until moderate thickness is achieved and an abrupt relaxation of tensile stresses when the films become very thick. The compressive range is consistent with a gradual relaxation of pseudomorphic growth, given that the lattice parameters of $\mathrm{GaN}, \mathrm{AlN}$, and $6 \mathrm{H}-\mathrm{SiC}$ at the growth temperature are $3.204,3.130,{ }^{17}$ and $3.092 \AA{ }^{18}$ respectively. The tensile range is presumably a thermal contraction effect, since both AlN and GaN $(\Delta a=0.17$ and $0.16 \AA$, respectively) shrink more than $6 \mathrm{H}-\mathrm{SiC}(\Delta a=0.11 \AA)$ upon cooling to low temperature. The weakly tensile regions for $d>$ $\sim 2.5 \mu \mathrm{m}$ is consistent with the idea that for sufficiently thick films an underlying interface is no longer able to withstand the stress and an abrupt relaxation occurs.

Other evidence supports this picture. While crosssectional transmission electron microscopy (TEM) micrographs show that the AlN/6H-SiC and GaN/AlN interfaces of these films are heavily dislocated $\left(\sim 10^{12} / \mathrm{cm}^{2}\right),{ }^{19,20}$ and

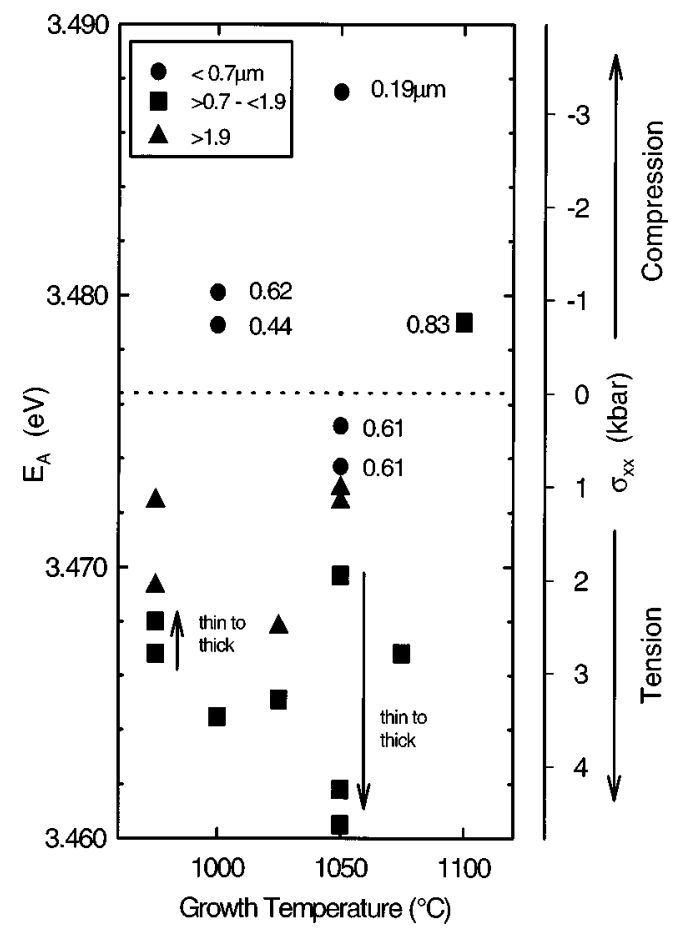

FIG. 2. The data in this figure vs growth temperature for on-axis $6 \mathrm{H}-\mathrm{SiC}$ samples. The arrows denote the progression in tensile stress with increasing

thickness for moderately thick films (squares) at 975 and $1050^{\circ} \mathrm{C}$.

oaded 16 Apr 2008 to 1521.24 .180 . Redistribution subject to

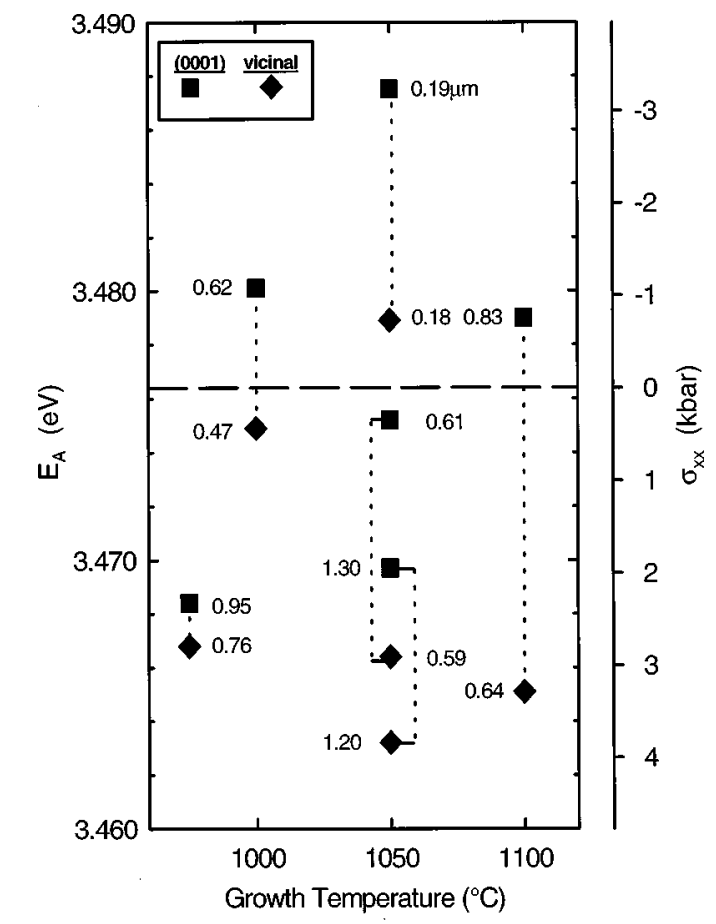

FIG. 3. $E_{A}$ and $\sigma_{x \underline{x}}$ vs growth temperature for growth on (0001) and vicinal $\left(3^{\circ}-4^{\circ}\right.$ toward $\left.[1120]\right) 6 \mathrm{H}-\mathrm{SiC}$. The numbers indicate film thicknesses in $\mu \mathrm{m}$. Sample pairs linked by dotted lines were grown at the same time under identical growth conditions.

calculated critical thicknesses of these layers are 46 (Ref. 21) and $12 \AA,{ }^{19}$ respectively, high-resolution micrographs show that the films are not fully relaxed. ${ }^{19}$ This follows from the scatter of Fig. 2 in Ref. 5, and our reflection-difference (RD) data, ${ }^{22}$ which shows evidence for anisotropic relaxation. Furthermore, calculated coherency stresses at the GaN/AlN interface $\left(\sigma_{x x}=56.5 \mathrm{kbar}\right.$ and $\left.\sigma_{y y}=54.8 \mathrm{kbar}\right),{ }^{19}$ are sufficiently large to reasonably account for residual stresses of an order of magnitude less after initial relaxation processes occur and a multiplicity of defects with different Burgers vectors have been observed within a selection of representative films ${ }^{20}$ a possible indication that different slip mechanisms could be activated as forces accumulate within a heterostructure with increasing GaN layer thicknesses. We will discuss elsewhere the possibility that film stresses generated by lattice and thermal mismatch are more complex than previously assumed. ${ }^{23}$

The effect of growth temperature on these processes is shown for on-axis (0001) 6H-SiC samples in Fig. 2, and the additional influence of substrate orientation is shown in Fig. 3. Three trends are apparent: First, from Fig. 2 the thickness at which compressive stress changes to tensile appears to vary with growth temperature. The $\sim 0.6 \mu \mathrm{m}$ films are slightly tensile at $1050^{\circ}$ and are slightly compressive at $1000^{\circ} \mathrm{C}$, and at $1100^{\circ} \mathrm{C}$, a moderately thick sample is compressive, unlike those grown at lower temperatures. Second, a $1050{ }^{\circ} \mathrm{C}$ the tension in moderately thick samples increases with increasing thickness while the reverse appears to be true at $975^{\circ} \mathrm{C}$. Third, we see that the range of stress over which these processes occur appears to increase with increasing growth temperature.

It seems plausible that at any given temperature any film will follow the same general trend of progressive relaxation 
shown in Fig. 1, although the specific values of thicknesses and range parameters will vary with growth temperature. Granted, we have not examined enough samples to confirm this hypothesis, but it would explain the apparently unusual progression of stress with increasing thickness at $1050{ }^{\circ} \mathrm{C}$ as opposed to the behavior at lower temperatures.

The effect of substrate offcut angle on the relationship between residual stress and growth temperature is shown in Fig. 3. Data are given for six pairs, each of which consists of one sample grown on an on-axis substrate (squares) and the other on a substrate offcut $3^{\circ}-4^{\circ}$ toward [1120] (diamonds). Members of each pair were grown simultaneously. In each case, the vicinal sample is more tensile (or less compressive) and thinner than its on-axis counterpart. Here, as in Fig. 2, higher growth temperatures yield greater stress differences for each pair. Vicinal substrates have more surface steps to act as sites for the generation of dislocations, and therefore for stress relief, yet a variety of stresses for the six vicinal samples are achieved. Initial relaxation mechanisms appear partial here as well. Additionally, growth rates are slower for vicinal samples, while the reverse is generally true for other materials. The difference between $\mathrm{GaN}$ on- and off-axis growth rates suggests that cation desorption is promoted by steps, whereas cation desorption is not generally a factor for non-nitride III-Vs where the growth temperatures are much lower.

Clearly, further work is needed to quantify and understand relaxation phenomena in these heterostructures, as the wide variety of stresses achieved here indicates. It appears that the $6 \mathrm{H}-\mathrm{SiC}$ substrate/high temperature AIN buffer layer combination enables a wide variety of options for tailoring stress states in GaN layers, potentially of use in valence band engineering applications. This aspect will be discussed elsewhere.

The authors would like to acknowledge the financial support of the Office of Naval Research (ONR) under Contract No. N-00014-93-1-0255. F. G. McIntosh is acknowledged for several helpful discussions.

${ }^{1}$ R. Dingle, D. D. Sell, S. E. Stokowski, and M. Ilegems, Phys. Rev. B 4, 1211 (1971).

${ }^{2}$ W. Shan, T. J. Schmidt, X. H. Yang, S. J. Hwang, J. J. Song, and B. Goldenberg, Appl. Phys. Lett. 66, 985 (1995).
${ }^{3}$ I. A. Buyanova, J. P. Bergman, B. Monemar, H. Amano, and I. Akasaki, Appl. Phys. Lett. 68, 1255 (1996).

${ }^{4}$ B. J. Skromme, H. Zhao, B. Goldenberg, H. S. Kong, M. T. Leonard, G. E. Bulman, C. R. Abernathy, and S. J. Pearton, Mater. Res. Soc. Symp. Proc. 449 (1996).

${ }^{5}$ N. V. Edwards, S. D. Yoo, M. D. Bremser, T. W. Weeks, Jr., O. H. Nam, H. Liu, R. A. Stall, M. N. Horton, N. R. Perkins, T. F. Kuech, and D. E. Aspnes, Appl. Phys. Lett. 70, 2001 (1996).

${ }^{6}$ It should be noted that Krueger and co-workers have recently achieved an impressive range of compressive stresses on $\mathrm{Al}_{2} \mathrm{O}_{3}$ substrates by varying various growth parameters. However, these are still within the realm of expected behavior for this substrate choice. J. Krueger, G. S. Sudhir, D. Corlatan, Y. Cho, Y. Kim, R. Klockenbrink, S. Rouvimov, Z. LilientalWeber, C. Kiesielowski, M. Rubin, and E. R. Weber, Mater. Res. Soc. Symp. Proc. (in press).

${ }^{7}$ T. W. Weeks, Jr., M. D. Bremser, K. S. Ailey, E. Carlson, W. G. Perry, and R. F. Davis, Appl. Phys. Lett. 67, 401 (1995).

${ }^{8}$ S. D. Yoo, N. V. Edwards, and D. E. Aspnes, Thin Solid Films 313-314, 143 (1998).

${ }^{9}$ H. Amano, K. Hiramatsu, and I. Akasaki, Jpn. J. Appl. Phys., Part 2 27, L1384 (1988).

${ }^{10}$ T. Detchprohm, K. Hiramatsu, K. Itoh, and I. Akasaki, Jpn. J. Appl. Phys., Part 2 31, L1454 (1992).

${ }^{11}$ Landolt-Börnstein, edited by O. Madelung (Springer, New York, 1982), Vol. 17.

${ }^{12}$ Properties of Group III Nitrides, edited by J. H. Edgar (INSPEC, London, 1994).

${ }^{13}$ W. Shan, R. J. Hauenstein, A. J. Fischer, J. J. Song, W. G. Perry, M. D. Bremser, R. F. Davis, and B. Goldenberg, Phys. Rev. B 54, 13460 (1996).

${ }^{14}$ D. Volm, K. Oettinger, T. Streibl, D. Kovalev, M. Benchorin, J. Diener, B. K. Meyer, J. Majewski, L. Eckey, A. Hoffman, H. Amano, I. Akasaki, K. Hiramatsu, and T. Detchprohm, Phys. Rev. B 53, 16543 (1996).

${ }^{15}$ K. Hiramatsu, T. Detchprohm, and I. Akasaki, Jpn. J. Appl. Phys., Part 1 32, 1528 (1993).

${ }^{16}$ Consistent with previously reported XRD and TEM measurements on these samples, though Perry and co-workers found six compressive samples. Possible explanations are differing penetration depths of the probe beams and different measurement temperatures. W. G. Perry, T. Zheleva, M. D. Bremser, R. F. Davis, W. Shan, and J. J. Song; J. Electron. Mater. 26, 224 (1997).

${ }^{17}$ K. Wang and R. R. Reeber, Mater. Res. Soc. Symp. Proc. (in press).

${ }^{18} \mathrm{~A}$. Taylor and R. M. Jones, in $\mathrm{SiC}$, edited by J. R. O'Connor and J. Smiltens (Pergamon, Oxford, 1960), p. 147.

${ }^{19}$ T. Zheleva and R. F. Davis (unpublished).

${ }^{20}$ F. R. Chien, X. J. Ning, S. Stemmer, P. Pirouz, M. D. Bremser, and R. F. Davis, Appl. Phys. Lett. 68, 2678 (1996).

${ }^{21}$ S. Tanaka, R. S. Kern, and R. F. Davis, Appl. Phys. Lett. 66, 37 (1995).

${ }^{22}$ U. Rossow, N. V. Edwards, M. D. Bremser, R. S. Kern, H. Liu, R. F. Davis, and D. E. Aspnes, Mater. Res. Soc. Symp. Proc. 449 (1996).

${ }^{23}$ N. V. Edwards, M. D. Bremser, R. F. Davis, A. D. Batchelor, and D. E. Aspnes (unpublished). 